\title{
Relationship between urban tourism traffic and tourism land use: A case study of Xiamen Island
}

\author{
Yueer Gao (corresponding author) \\ Huaqiao University \\ gaoyueer123@gmail.com \\ Donggen Wang \\ Hong Kong Baptist University \\ dgwang@hkbu.edu.hk
}

\author{
Yanqing Liao \\ Huaqiao University \\ lyq9963@126.com \\ Yongguang Zou \\ Huaqiao University \\ ygzou2009@126.com
}

Abstract: The development of tourism leads to changes in land-use demands and patterns, which are complex and dynamic, in tourist cities. Functional differences in land use produce different travel needs and have different impacts on traffic, especially on tourism. This paper explores the relationship between tourism land use and tourism traffic. Taking Xiamen Island as an example, using multivariable linear regression models, tourism land use is divided into accommodation land use, shopping land use and restaurant land use as the independent variables of the model; and the origin-destination (OD) density of traffic analysis zones (TAZs) during National Day in 2018 (October 1 to 5) is chosen as the dependent variable. To compare the different impacts between tourism land use and tourism traffic during the tourism and nontourism periods, the non-tourism period (March 11 to 15) is further studied. The results show the following: (1) Xiamen, as a tourism city, has not only regular traffic but also tourism traffic, and traffic during the tourism period is totally different than that in the non-tourism period. (2) Tourism land use has a considerable impact on both tourism traffic and non-tourism traffic, but the impact is greater during the tourism period than the non-tourism period. (3) In the morning peak hour of both the tourism period and the non-tourism period, accommodation land use shows prominent effects on traffic. In the evening peak hour, shopping land use significantly impacts traffic. The study provides a basis for urban tourism land use adjustment to achieve the sustainable development of tourism traffic.

\section{Article history:}

Received: May 14, 2020

Received in revised form:

February 22, 2021

Accepted: April 19, 2021

Available online: June 30, 2021

\section{$1 \quad$ Introduction}

With the rapid development of the economy and society and the continuous improvement of people's living standards, an increasing number of people are choosing to travel on holidays. Tourism plays an increasingly important role in many aspects of human life. The concept of urban tourism defines a complex tourist system, which is mainly concentrated in urban areas and includes all the conditions and performances of tourist activities in the region, considering the tourist attraction of urban space (Łapko, 2014). Essentially a geographic phenomenon, tourism includes people's mobility (seen as the demand side) and spatial distribution patterns related to land use consumption (seen as the supply side)

Copyright 2021 Yueer Gao,Yanqing Liao, Donggen Wang \& Yongguang Zou

http://dx.doi.org/10.5198/jtlu.2021.1799

ISSN: 1938-7849 | Licensed under the Creative Commons Attribution - Noncommercial License 4.0

The Journal of Transport and Land Use is the official journal of the World Society for Transport and Land Use (WSTLUR) and is published and sponsored by the University of Minnesota Center for Transportation Studies. 
(Boavida-Portugal, Rocha, \& Ferreira, 2016). In tourist cities, both visitors and tourism service facilities are concentrated. In order to meet the tourism demand, tourists need to travel to places where tourism services are provided. The spatial movement caused by meeting the tourism demand will gather in a certain time and area, which will have a negative impact on urban traffic. Thus, the surge in tourism traffic is regional and closely related to tourism land use. Due to the overlapping of tourism traffic and urban traffic in tourist cities, the urban traffic system is subject to tremendous pressure, increasing the severity of traffic problems. Therefore, it is necessary to study the problem of tourism traffic in cities.

The nature of land use is related to the location of human activities, and traffic originates from the movement of human beings in different land uses. Therefore, the relationship between land use and transportation, which is relatively complex, is expressed by human mobility. Changes in the nature of land use or the land use function structure will inevitably impact traffic. Zhu, Xiong, Chen, He, and Zhang (2018) stated that the greater the intensity of land use development, the greater the average travel time index will increase without changing the departure time. That is, the greater the intensity of land use development, the greater the traffic generation and attraction, resulting in slow traffic and increased travel time. In tourist cities, the purpose of tourism traffic is to meet the demands of different tourist activities. Therefore, the influence of land use differences on tourism traffic cannot be overlooked, and the use of any piece of land will stimulate new traffic demands. The change in tourism land use will stimulate tourists' activities, thus having an impact on urban tourism traffic by generating new demands for transportation infrastructure. Therefore, in the tourism development process, it is necessary to coordinate the relationship between tourism land use and tourism traffic. This paper studies and quantifies the connection between urban tourism land use and urban tourism traffic and discusses the factors affecting tourism traffic. The structure of the remainder of this paper is as follows: Section 2 summarizes the progress of the research on tourism and land use, tourism and transportation, and land use and transportation. In Section 3, a multivariable linear regression model is proposed to evaluate the impact of land use with different functions on traffic during non-tourism periods and tourism periods. Section 4 determines the research area where tourism traffic is mainly generated. Section 5 introduces and discusses the results of the regression model of tourism land use and non-tourism traffic and tourism traffic in Xiamen. Then, Section 6 draws a conclusion.

\section{$2 \quad$ Literature review}

Tourism land use is a dynamic and complex land use mode. The strong growth of the tourism industry is accompanied by changes in its form and distribution and the relationship with other land uses, which is determined by demographic and social changes, consumer behavioral trends, technological and transport changes, and the evolution of governance and policy (Williams \& Shaw, 2009). Bi (2015) established a model of land use efficiency by using MATLAB and studied the relationship between land use efficiency and the ecological benefits of ecotourism. Marzuki, Masron, and Ismail (2015) applied spatial patch analysis to analyze land use change in tourist areas. Mao, Meng, and Wang (2014) employed a system dynamic-cellular automata hybrid model to study the effects of tourism on land use change and how land regulation policies integrate tourism development with land use. Xi, Zhao, Ge, and Kong (2014) combined participatory rural assessment methods, geographic information systems (GISs) and remote sensing to explore the spatial and temporal patterns of the land use change in tourist villages in China from 1986 to 2010. Based on GPS vehicle trajectory data and land use information around vehicles from open source data, Krause and Zhang (2019) deduced the purpose of tourists' travel. Closely related to tourism, land use has a certain impact on the tourism environment and tourism ecology. Therefore, addressing the relationship between land use and tourism development is conducive 
to the development of urban tourism, thus bettering the tourist experience and enhancing the vitality and attractiveness of a city.

Different types of land use impact traffic. Many scholars have studied the relationship between different types of land use and traffic (Han, 2012; Liu, Wang, Xiao, \& Gao, 2012; Mao et al., 2014). Generally, commercial land use has a negative impact on traffic. The increase in regional employment density and the number of commercial facilities means more business districts, resulting in greater traffic generation and attraction, which will eventually lead to more frequent travel demand, increased traffic generation and attraction and restrained traffic speeds (Pulugurtha, Duddu, \& Kotagiri, 2013; Wang et al., 2019). However, for tourism cities, the diversification of industries with different components, such as hotels, restaurants and shopping plazas, makes tourism land use more complex. In addition, tourists have more frequent travel needs on holidays and have a greater demand for tourism service facilities, and the development and layout of tourism land use has a more significant impact on tourism traffic. In such a situation, researchers began to explore the relationship between tourism development and land use.

The relationship between tourism land use and the degree of urban traffic generated and attracted is complicated, and the methods used to study land use and urban traffic are multifarious in the existing literature. Alaigba, Soumah, and Banjo (2017) selected the heterogeneity index to determine the distribution of land use patterns and the impact of land use types on traffic congestion. The results show that there was a marked correlation between the degree of heterogeneity of land use patterns and the degree of road traffic congestion. Zhang, Sun, Yao, and Rong (2017) studied the connection between land use and congestion time using multivariable linear regression analysis. The results show that a reasonable proportion of land use types can effectively shorten the time stuck in traffic. Gan, Feng, Wu, Yang, and Timmermans (2019) used the average travel distance of a site and the quantile regression model to analyze spatiotemporal urban mobility patterns and their relationships with urban form and land use.

A literature review shows that despite the growing literature on the relationship between land use and urban traffic, explanations of the relationship between different land use properties and tourism traffic while discussing the impact of land use on traffic are very limited. The existing studies mainly focus on daily residents' travel, neglecting tourism periods, which are different from the general situation. As a large number of tourists pour into a city during a tourism period, it brings more pressure to urban traffic. To solve the problem of tourism traffic, which is rooted in tourism land use attraction to visitors, it is necessary to address its relationship with tourism land use. Therefore, the study of tourism traffic and tourism land use has a great bearing on how to combine land use and tourism development to improve land use efficiency and alleviate traffic problems. In this study, by establishing a multivariable linear regression model, combined with tourism land use, the impact of tourism land use on tourism traffic being generated and attracted was explored according to the traffic generation and attraction during the tourism period. The purpose of this study is to enable urban planners and decision makers to better understand how tourism directly and indirectly affects tourism traffic generation and attraction.

\section{Data sources and methodology}

Land use characteristics are usually calculated using fixed spatial units, such as TAZs (traffic analysis zones) (Gan et al., 2019). The data used in this paper are the vectoral area data of TAZs, the POI (Point of Interest) data of tourism service facilities in Xiamen, and the OD (Origin-Destination) data of the tourism period and non-tourism period. The OD data are from Floating Car Data (FCD) and contain information on on/off time, coordinate points, driving distance and other data.

Xiamen received a total of 2.3 million domestic and foreign tourists during National Day, up $16.14 \%$ from the same period last year (Xiamen Municipal Bureau of Culture and Tourism, 2018). The 
OD data from October 1 to 5 of Chinese National Day in 2018 are selected as the research data, and data from March 11 to 15 are selected as the control group. The data of the days are counted by hour, as shown in Figure 1. The figure shows that the peak hours during the tourism period are inconsistent with those during the non-tourism period, and the number of ODs for the tourism period is much greater than that of the non-tourism period. The morning peak in the non-tourism period occurred earlier than that in the tourism period, and the evening peak occurred later than that in the tourism period. Since a full-time study may cover up the characteristics of different periods (Yu \& He, 2017) and this research is focused on tourism traffic, thus, the early peak hour 9:00-10:00 and evening peak hour 18:00-19:00 of the tourism period are selected as the study period for further study. Different from the previous study that used speed as the traffic indicator of peak hours (Gao, Chen, Zheng, \& Bian, 2016), the OD density of the TAZs of peak hours is chosen as the indicator of the study in order to reflect the quantitative relationship between tourism land use and tourism traffic.

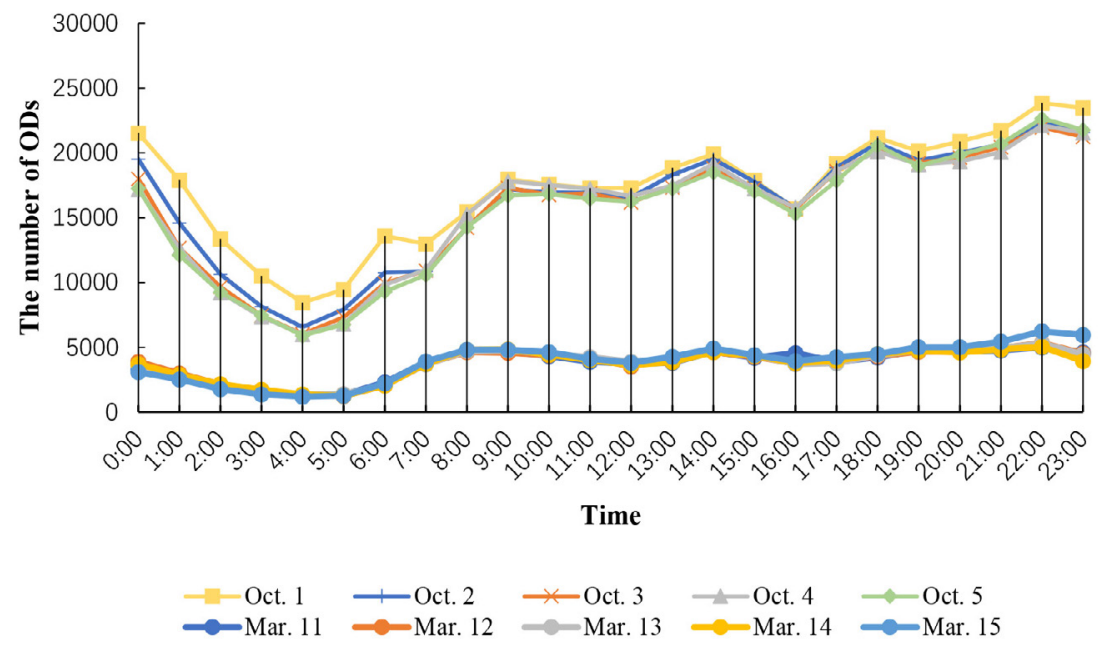

Figure 1. The number of OD in the tourism period (Oct. 1-5) and non-tourism period (Mar. 11-15)

This paper mainly studied and discussed the impact of tourism land use on tourism traffic, that is, the generation and attraction of tourism traffic based on accommodation land use, shopping land use and restaurant land use. Finally, based on the results of the multivariable linear regression model, the impacts of different types of tourism land use on tourism traffic are described.

\subsection{Distribution of tourism service facilities and tourists' travel}

In order to better understand the temporal and spatial distribution differences of traffic between the tourism period and non-tourism period, spatial analysis is conducted. In this paper, kernel density estimation (KDE) is used to visualize the tourism service facilities and the travel distribution of tourists. Kernel density estimation is a density function used to estimate the unknowns in probability theory. Mainly based on quadratic kernels, it is used to estimate the unknown density function and to reflect the distribution characteristics of feature points. The formula is as follows:

$f(x, y)=\frac{1}{\mathrm{nh}^{2}} \sum_{\mathrm{i}=1}^{\mathrm{n}} \mathrm{nk}\left(\frac{\mathrm{d}_{\mathrm{i}}}{\mathrm{h}}(\mathrm{x}, \mathrm{y})\right)$

In formula (1), $f(\mathrm{x}, \mathrm{y})$ is the density estimation of position $(\mathrm{x}, \mathrm{y}) ; \mathrm{n}$ is the observed value; $\mathrm{h}$ is the bandwidth or smoothness index; $d_{i}(\mathrm{x}, \mathrm{y})$ is the distance between position $(\mathrm{x}, \mathrm{y})$ and the first observed po- 
sition; and $\mathrm{k}$ is the weight function (also known as the kernel function), which conforms to Tobler's first law of geography. In fact, each local weighting process in $\mathrm{KDE}$ is estimated by its influence on distance decay events. Distance is usually defined as a straight line or the Euclidean distance (Yu, Ai, \& Shao, 2015). There is spatial agglomeration of tourism service facilities. The higher the degree of agglomeration is, the larger the scope of its influence and the greater the attraction to tourists.

\subsection{Multivariable linear regression model}

The question of this paper is whether there is a relationship between tourism land use and tourism traffic. In order to probe this issue, the multivariate linear regression is selected to study the relationship between the tourism land use and tourism traffic. A multivariate linear regression is a model in which multivariable regression independent variables are used to interpret and estimate dependent variables. The general expressions of multivariate linear regression models are as follows:

$\mathrm{y}=\beta_{0}+\beta_{1} x_{1}+\beta_{2} x_{2}+\cdots \beta_{p} x_{p}+\varepsilon$

Among the variables, $\beta_{0}$ is a constant term; and $\beta_{1}, \beta_{2}, \ldots \beta_{p}$ are the regression coefficients. In this paper, the accommodation land use, shopping land use and restaurant land use of TAZs are selected as the independent variables; and the OD density of TAZs is regarded as the dependent variable. The descriptions of the variables are shown in Table 1 . To better represent the relationship between similar tourism land uses, the Variance Inflation Factor (VIF) is calculated to test the collinearity of the variables. If the VIF is greater than 10, it means that the variables are collinear. As shown in Table 1, the VIF values are much smaller than 10 , indicating that there is no collinearity between variables.

Table 1. Description of variables

\begin{tabular}{lll}
\hline Variables & Description & VIF \\
\hline Accommodation land use & Accommodation room density of TAZs & 1.644 \\
Shopping land use & Proportion of shopping land use in TAZs & 1.894 \\
Restaurant land use & Restaurant POI Density of TAZs & 1.261 \\
Traffic generation and attraction & OD Density of TAZs & - \\
\hline
\end{tabular}

\section{Determination of research area}

Xiamen is an international seaport scenic city and a famous tourist city in China with a population of approximately 4.11 million. Located in South Fujian Bay and covering an area of approximately 158 $\mathrm{km}^{2}$ with a population of approximately 1.1 million, Xiamen Island is rich in tourism resources and represents the core tourism area and the service center of Xiamen. In addition, Xiamen Island's tourist attractions are mainly distributed in the southern coastal area of the island. Its unique geographical location has attracted many domestic and foreign tourists, and the demand for tourism traffic has also increased rapidly, bringing greater pressure to urban transportation systems.

In this paper, $\mathrm{KDE}$ is used to determine the research area. Regarding the $\mathrm{KDE}$ results (as shown in Figure 2), the larger the kernel density is, the brighter the color, indicating more tourism service facilities in the region. Taking TAZs as the research unit, the research scope is determined by the zonal statistics, and the $\mathrm{KDE}$ results of tourism service facilities are divided into six categories according to the mean value. The results are shown in Figure 2. Most TAZs with a KDE greater than 104.99 are considered 
within the research scope (as shown in Figure 3). However, although the mean values of TAZ nos. 81 and 82 are small, they are considered research TAZs because there are many popular scenic spots and tourist service facilities. Furthermore, there are no well-known scenic spots in TAZ nos. 9, 10, 11 and 23 and these areas are mainly residential areas, so they are excluded from the research scope. There are 82 TAZs on Xiamen Island, and 37 of them are identified as the research scope of the study. In addition, the floating car OD data produced in the research scope accounted for approximately $50 \%$ of Xiamen.
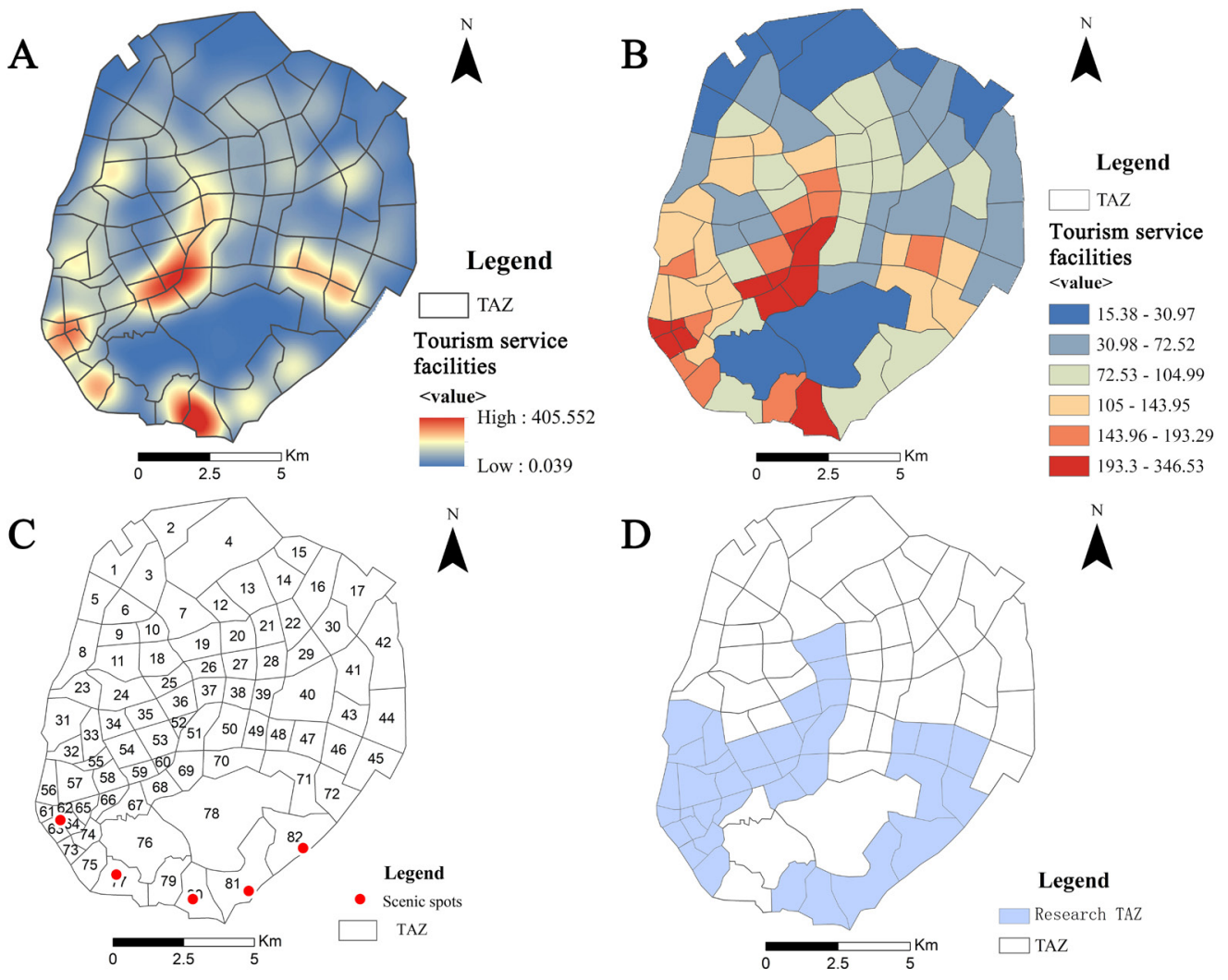

Figure 2. Determination of the research scope: A) kernel density estimate of tourism service POI; B) KDE mean value of tourism service facilities of TAZs; C) TAZs on Xiamen Island; and D) research scope)

\section{$5 \quad$ Results}

In order to explain the relationship between tourism land use and tourism traffic generation and attraction, a non-tourism period is established as a control group in section 5.1, that is, the impact of tourism land use on urban traffic during the non-tourism period. Then, section 5.2 shows the regression results of tourism land use and tourism traffic. In addition, the OD distribution and connection among tourism main nodes during the tourism period and non-tourism period are compared in sections 5.3 and 5.4 to explain the different impacts of tourism land use on urban traffic and tourism traffic.

\subsection{The impact of tourism land use on urban traffic during the non-tourism period}

A strong linear relationship is defined as $\mathrm{R}^{2}>0.6$. A moderate linear relationship is defined as $0.4 \leq \mathrm{R}^{2}$ $\leq 0.6$. A weak linear relationship and statistically nonsignificant linear relationship are defined as $\mathrm{R}^{2}<0.4$ and $\mathrm{p} \geq 0.1$, respectively (Spyratos \& Stathakis, 2017). The $\mathrm{R}^{2}$ of the model is between 0.48 and 0.70 (as 
shown in Table 2), and most of the $\mathrm{R}^{2} \mathrm{~s}$ are below 0.6, which means that tourism land use has a moderate linear relationship with urban traffic during the non-tourism period. The results show that the impact of tourism accommodation land use, shopping land use and restaurant land use on urban traffic is significant during the non-tourism period.

According to the coefficients, accommodation land use, followed by shopping land use and restaurant land use, has the largest impact on urban traffic during the non-tourism period. The impact of tourism accommodation land use is significant because there are people who travel to Xiamen Island for business, and perhaps there are also a small number of tourists. Shopping land use and restaurant land use have significant impacts on urban traffic during the non-tourism period because these types of tourism service facilities not only serve tourists but also locals. However, restaurant land use is only significant in the evening peak of one day and is nonsignificant on the other four days. This indicates that restaurant land use may not necessarily attract and generate more trips. In addition, people often feel mentally exhausted on the first day of weekdays because they need to adjust from a weekend vacation to a working state, so they would like to have dinner outside after work.

Table 2. Results of the regression model of non-tourism peak hour

\begin{tabular}{|c|c|c|c|c|c|}
\hline \multicolumn{6}{|c|}{ Morning Peak Hour } \\
\hline Independent variables & Mar. 1 & Mar. 2 & Mar. 3 & Mar. 4 & Mar. 5 \\
\hline Accommodation land use & $0.670^{* * *}$ & $0.718^{* * *}$ & $0.732^{* * *}$ & $0.740^{* * *}$ & $0.653^{* * *}$ \\
\hline Shopping land use & 0.202 & 0.127 & 0.143 & 0.072 & $0.255^{*}$ \\
\hline Restaurant land use & -0.036 & -0.056 & -0.055 & -0.053 & -0.123 \\
\hline $\mathrm{R}^{2}$ & 0.533 & 0.531 & 0.563 & 0.534 & 0.476 \\
\hline Adjusted $\mathrm{R}^{2}$ & 0.491 & 0.488 & 0.523 & 0.492 & 0.428 \\
\hline \multicolumn{6}{|c|}{ Evening Peak Hour } \\
\hline Independent Variables & Mar. 1 & Mar. 2 & Mar. 3 & Mar. 4 & Mar. 5 \\
\hline Accommodation land use & $0.479^{* * *}$ & $0.629^{* * *}$ & $0.525^{* * *}$ & $0.560^{* * *}$ & $0.606^{* * *}$ \\
\hline Shopping land use & $0.291^{* * *}$ & $0.255^{* *}$ & $0.302^{* *}$ & 0.202 & $0.231^{* *}$ \\
\hline Restaurant land use & $0.269^{* *}$ & 0.077 & 0.065 & 0.186 & 0.174 \\
\hline $\mathrm{R}^{2}$ & 0.701 & 0.640 & 0.525 & 0.619 & 0.701 \\
\hline Adjusted $\mathrm{R}^{2}$ & 0.674 & 0.607 & 0.481 & 0.584 & 0.674 \\
\hline
\end{tabular}

\subsection{The impact of tourism land use on urban traffic during the tourism period}

The regression results of tourism land use and traffic during the tourism period are shown in Table 3 . The $\mathrm{R}^{2} \mathrm{~s}$ of the model are between 0.56 and 0.72 , and most of them are larger than 0.6 , indicating that there is a strong linear relationship between tourism land use and tourism traffic during the tourism period and that the model can be used to explain the change in tourism traffic generation and attraction.

According to Table 3, during the peak of the tourism period, the impact of accommodation land use on tourism traffic is particularly significant during the study period, and it is followed by the impact of shopping land use on tourism traffic. In addition, the impact of restaurant land use on tourism traffic is not significant. Both accommodation land use and shopping land use are positively correlated with tourism traffic, indicating that tourism traffic will increase as accommodation land use and shopping land use increase. Tourism accommodations are concentrated around tourist attractions on Xiamen 
Island (see Figure 3), so there is more traffic demand during the morning and evening peak hours. In the evening peak period, shopping land use has a significant impact on tourism traffic. As the proportion of shopping land use increases, tourism traffic generation and attraction increase, which may form local agglomerations and lead to traffic congestion. Shopping is not the main purpose of tourists during morning peak hours, but shopping activities increase during evening peak hours. Hence, the impact of shopping land use on tourism traffic in the evening is more significant than that in the morning peak hours. In addition, according to the coefficients of the variables, accommodation land use and shopping land use have greater impacts on traffic during the tourism period than during the non-tourism period.

Table 3. Results of the regression model of tourism peak hours

\begin{tabular}{cccccc}
\hline & \multicolumn{5}{c}{ Morning Peak Hour } \\
Independent variables & Oct. 1 & Oct. 2 & Oct. 3 & Oct. 4 & Oct. 5 \\
\hline Accommodation land use & $0.781^{* * *}$ & $0.818^{* * *}$ & $0.850^{* * *}$ & $0.854^{* * *}$ & $0.863^{* * *}$ \\
Shopping land use & 0.142 & 0.114 & 0.091 & 0.117 & 0.104 \\
Restaurant land use & -0.119 & -0.188 & -0.175 & -0.176 & -0.182 \\
$\mathrm{R}^{2}$ & 0.577 & 0.560 & 0.607 & 0.626 & 0.628 \\
Adjusted R & 0.538 & 0.520 & 0.571 & 0.592 & 0.595 \\
\hline Independent Variables & Oct. 1 & Evening Peak Hour & & & Oct. 5 \\
\hline Accommodation land use & $0.699^{* * *}$ & $0.724^{* * *}$ & $0.764^{* * *}$ & $0.737^{* * *}$ & $0.662^{* * *}$ \\
Shopping land use & $0.333^{* * *}$ & $0.302^{* * *}$ & $0.292^{* * *}$ & $0.279^{* *}$ & $0.343^{* * *}$ \\
Restaurant land use & -0.029 & -0.052 & -0.072 & -0.037 & 0.019 \\
$\mathrm{R}^{2}$ & 0.703 & 0.685 & 0.716 & 0.700 & 0.711 \\
Adjusted $\mathrm{R}^{2}$ & 0.676 & 0.657 & 0.690 & 0.673 & 0.685 \\
\hline
\end{tabular}

${ }^{* * *} \mathrm{p} \leq 0.01 .^{* *} \mathrm{p} \leq 0.05 .{ }^{*} \mathrm{p} \leq 0.1$
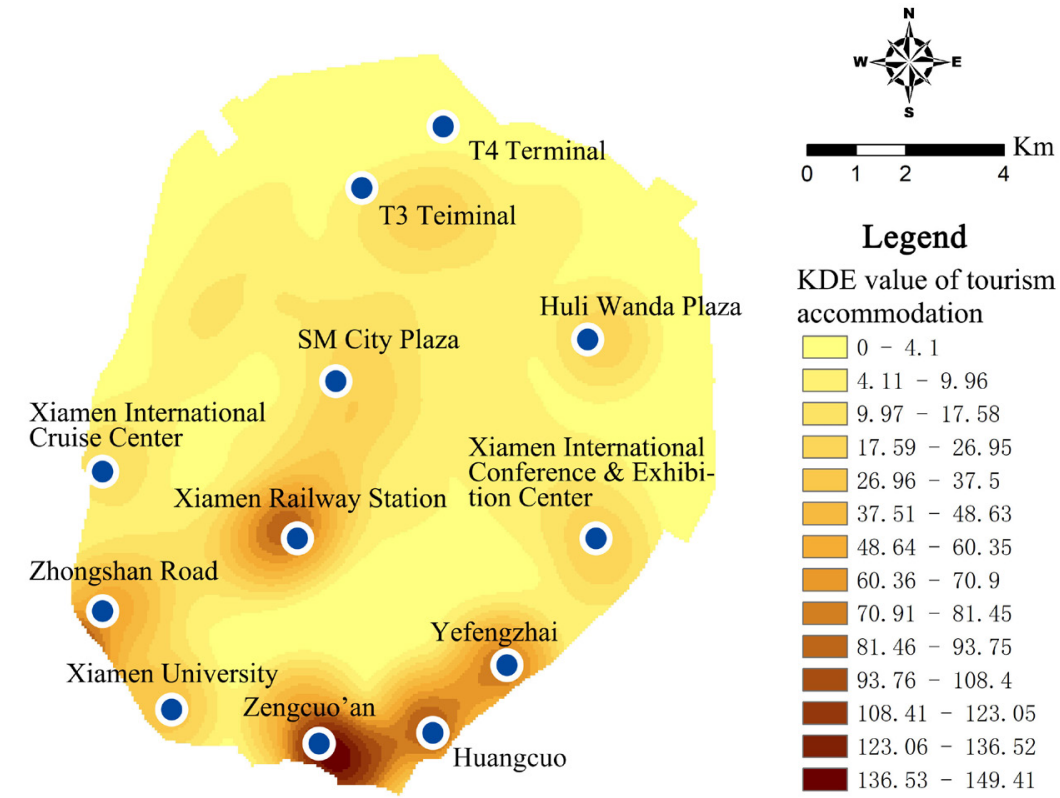

\section{Legend}

$\mathrm{KDE}$ value of tourism accommodation

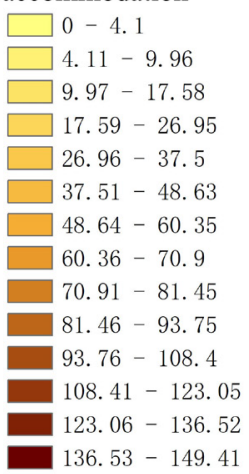

Figure 3. Kernel density estimate results for accommodations 
Although tourism land use has a significant impact on traffic during the tourism period and nontourism period, the impact in the tourism period is more prominent. That is, according to the coefficients, tourism land use has a greater impact on tourism traffic. In order to further compare the different impacts of tourism land use on traffic during the tourism period and non-tourism period, this paper further analyzes the spatial distribution of traffic during the two types of periods.

\subsection{Distribution of OD during tourism and non-tourism period}

The OD distribution shows the travel sources and purposes of tourists (as shown in Figure 4). Figure 4 shows that the traffic generation and attraction during the tourism period are much larger than those during the non-tourism period, which indicates that during the tourism period, the number of tourists coming to Xiamen Island for tourism is large, resulting in a heavy traffic demand. In addition, the traffic during the tourism period has the characteristics of local agglomeration, focusing on tourist attractions and transportation hubs.

In the morning peak hour of the tourism period (Figure 4-A), the origin points of tourists are mainly concentrated near Xiamen Railway Station, Zhongshan Road, Xiamen International Cruise Center and Gaoqi Airport. The destination points are mainly concentrated at Xiamen Railway Station, Xiamen International Cruise Center, Gaoqi Airport, Zhongshan Road and Xiamen University. In the evening peak hour of the tourism period (Figure 4-B), the origin and destination points of tourists are mainly concentrated at Xiamen Railway Station, Gaoqi Airport, Zhongshan Road, SM City Plaza and Ruijing Shopping Plaza. Xiamen Railway Station and Gaoqi Airport are the important external transportation hubs of Xiamen Island. In addition, Zhongshan Road, SM City Plaza and Ruijing Shopping Plaza are the main commercial areas of Xiamen. These commercial areas possess a variety of restaurant services and shopping services and can meet the needs of tourists.

In the morning peak hour of the non-tourism period (Figure 4-C), tourist origin points are mainly concentrated at Zhongshan Road, Xiamen Railway Station, Chaojiu Center, Software Park, SM City Plaza and some residential areas. The destination points are mainly concentrated at Gaoqi Airport, the Wuyuan Bay business district, Software Park, Huli Hi-tech Park, the Guanyinshan business district and other locations. These places are the main business districts of Xiamen city. In the evening peak hour of the non-tourism period (Figure 4-D), the origin points are mainly concentrated at Zhongshan Road, Xiamen Railway Station, SM City Plaza, and Ruijing Shopping Plaza. These places provide diverse restaurant services and shopping services with a comfortable environment to meet the consumption needs of residents after work.

Tourism traffic is mainly concentrated at urban attractions, transportation hubs and commercial areas. However, in the non-tourism periods, urban traffic is mainly concentrated in residential and business districts. Although tourism land use has a significant impact on tourism traffic during both the tourism period and the non-tourism period, the reasons for this impact are not the same. During the tourism period, there is no doubt that tourists have a greater demand for tourism service facilities. Although these service facilities mainly serve tourists, they also provide services for the surrounding residents. For example, SM City Plaza and Ruijing Shopping Plaza, as the main shopping plazas in Xiamen, are surrounded by residential areas. Therefore, in the evening, more local residents will visit those locations for consumption. In addition, because restaurant is one of the important aspects of people's lives, there are a large number of restaurant facilities that are widely distributed, leading to a nonsignificant impact on traffic during tourism periods and non-tourism periods. In addition, the traffic demand during the tourism period is much larger than that during the non-tourism period; and the increased traffic demand is mainly concentrated around urban attractions, transportation hubs and commercial areas. 
This has placed great pressure on the traffic system of tourist cities and has had a negative impact on the travel of residents in the old town (the location of the old town is shown in Figure 4).

A
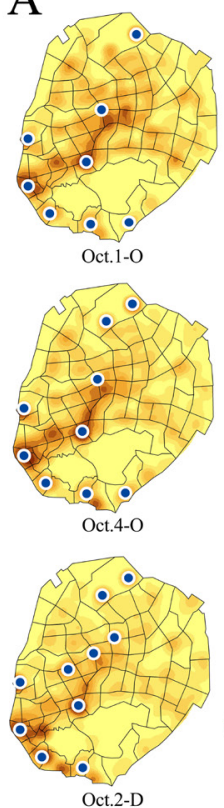

0
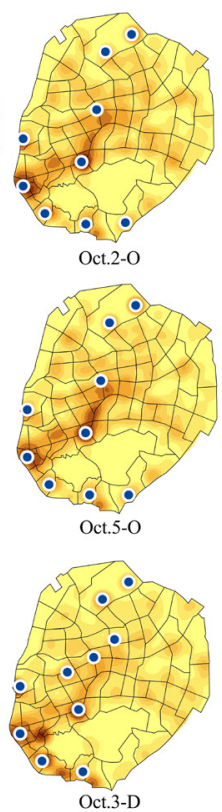

ct.3-D
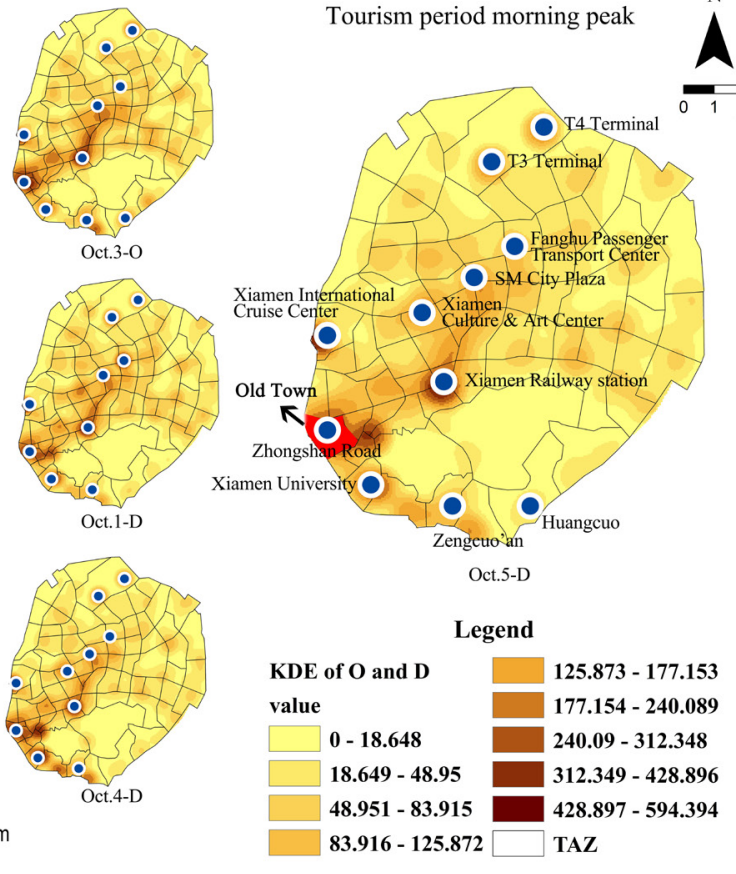

B
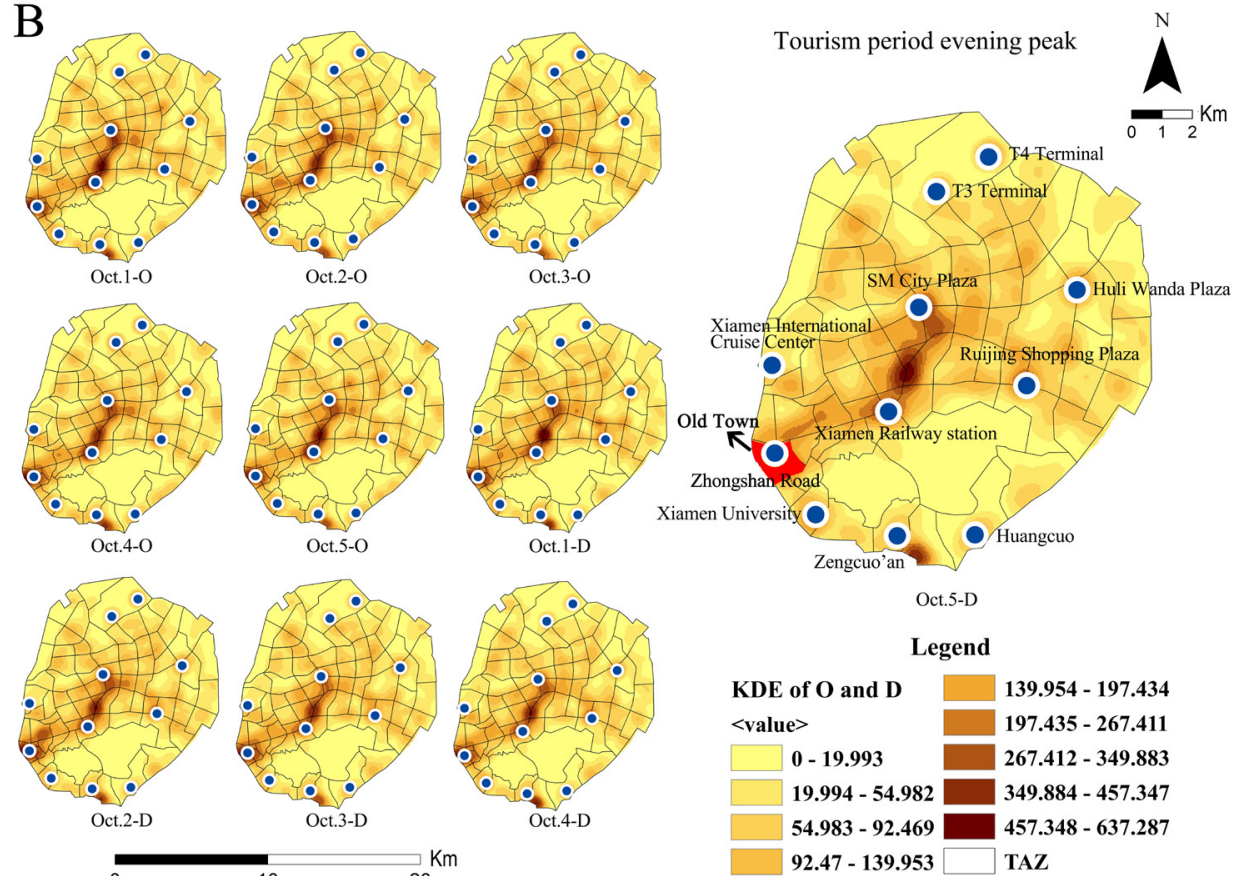

Legend

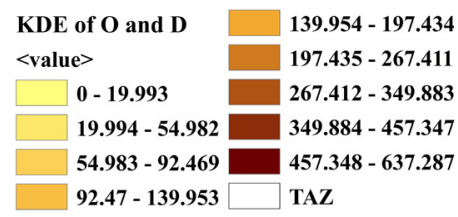



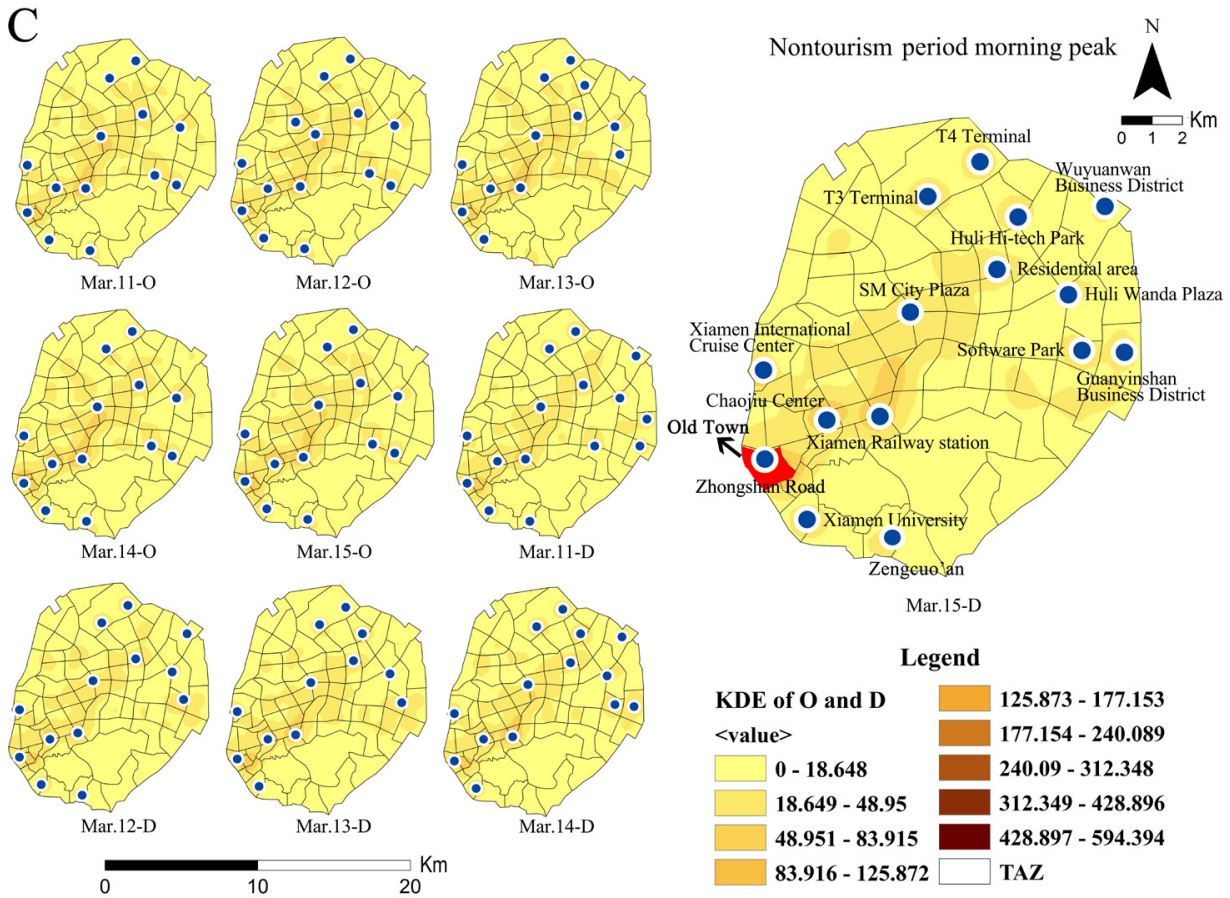

$\mathrm{D}$
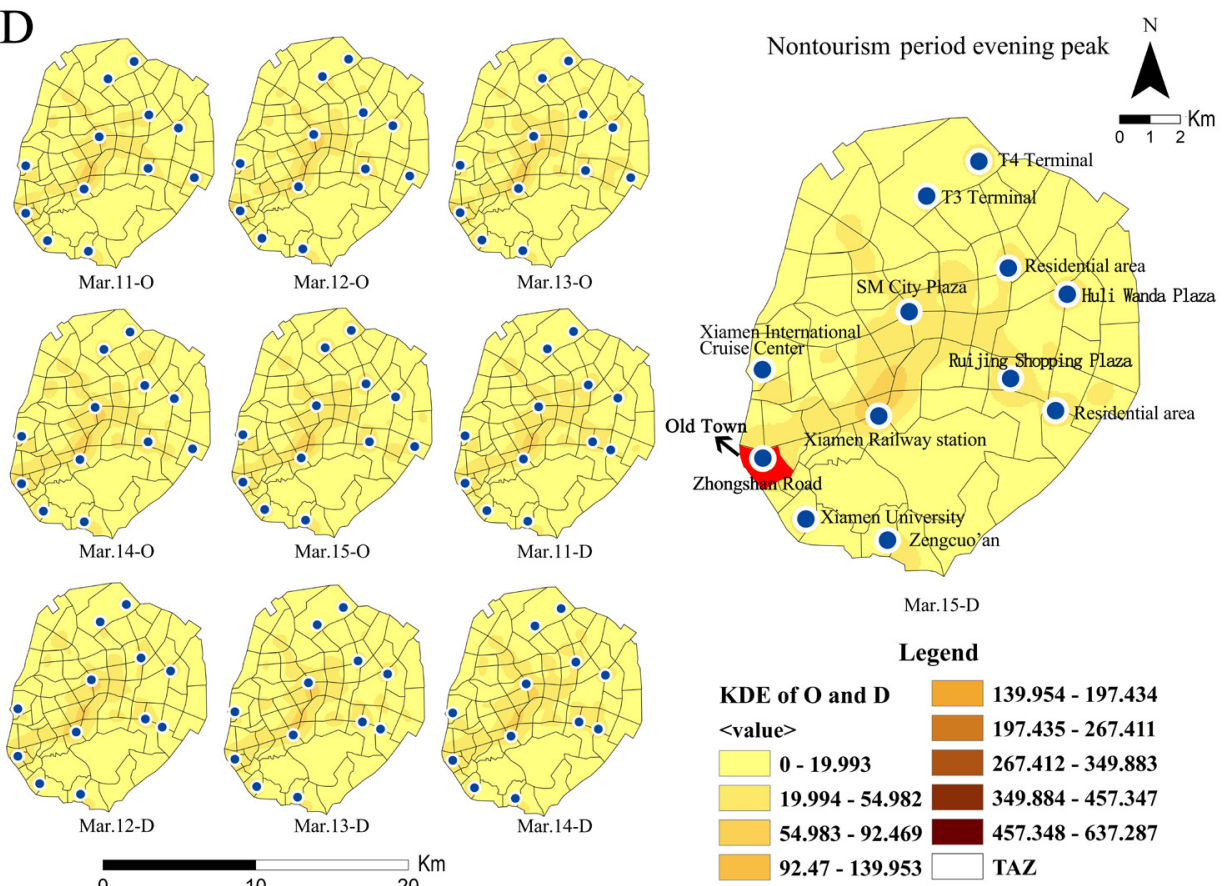

Figure 4. Spatial distribution of Os and Ds in the tourism morning peak and evening peak in the tourism period (A and B) and non-tourism period (C and D) 


\subsection{Connection between main travel nodes during the tourism period}

In order to better understand the impact of tourism land use on tourism traffic, the study draws a travel OD expectation diagram between the main travel nodes of the tourism period (as shown in Figure 5). The figure shows that at the peak hour of the day and night, tourists mainly gather at Zhongshan Road, Xiamen Railway Station, Zengcuo'an and several shopping plazas on Xiamen Island. Zhongshan Road is a historical and cultural scenic spot in Xiamen that is an important destination for tourists and provides a variety of tourism services for tourists. In addition, the sea view at night and the dim lights of pedestrian streets also attract many tourists. The Xiamen International Cruise Center is the only location that provides ferry services to tourists to Gulangyu during the day. Therefore, tourism traffic gathers there during morning peak hours. Xiamen Railway Station is the only railway hub on Xiamen Island; and due to its location in the central area of Xiamen Island, a large number of tourist accommodation, restaurants and shopping centers are gathered around it. Therefore, regardless of whether it is the morning or evening peak, the area surrounding the railway station can attract and generate a large amount of tourism traffic. In the morning, Zhongshan Road is closely connected with the Xiamen International Cruise Center, Xiamen University, Zengcuo' an and Xiamen Railway Station. In the evening peak hour, Zhongshan Road, Xiamen Railway Station, Zengcuo'an and shopping plazas are closely linked. Therefore, the impact of shopping land use on tourism traffic is significant in the evening peak hour.

On Xiamen Island, the Xiamen International Cruise Center has a larger passenger flow during the tourism period than during the non-tourism period because tourists can only take the ferry to Gulangyu during the day. In the past, tourists and residents went to Gulangyu through the Xiamen ferry terminal, which brought great traffic pressure to the old town. As docks are being relocated, tourists and residents are now traveling along different routes, reducing the traffic pressure in the old town. However, as the number of tourists and the concentrated distribution of tourism service facilities increase, traffic pressure still exists in the old town. In the evening peak hour, there are fewer trips between the Xiamen International Cruise Center and Zhongshan Road, Zengcuo'an, but the trips between Zhongshan Road and Xiamen Railway Station, Zengcuo'an and shopping plazas increased. This brings great traffic pressure to the old town and the transportation system.

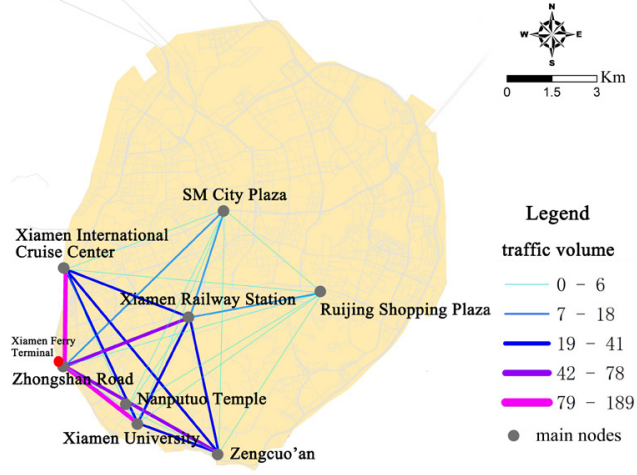

(a) Moring peak hour

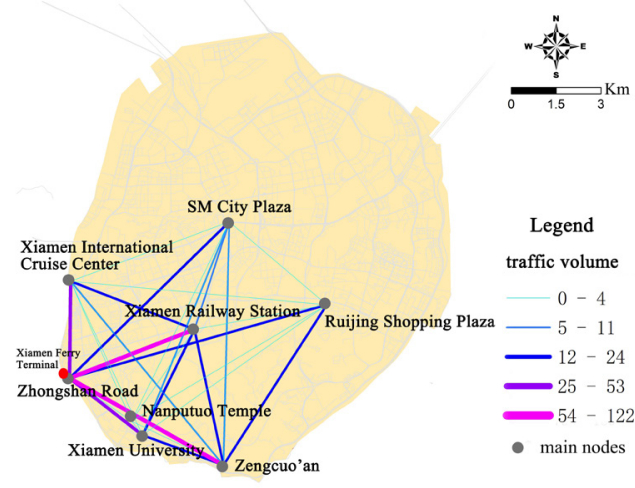

(b) Evening peak hour

Figure 5. The main flow of tourism traffic in the morning (a) and evening (b) peak hours during the tourism period 


\section{Conclusions}

Cities are now monitoring spatial details and long-term human activities through various channels, including land use and transport (Kii, Moeckel, \& Thill, 2019). People's spatial movement is related to specific urban activities and land use. Because of the different natures and functions of land use, transportation is an important way to connect different land use properties and reflects people's travel trajectories and purposes. Tourist cities attract a large number of visitors thanks to their abundant tourism resources. Tourists travel more frequently between different tourism land uses, having a great impact on traffic. Therefore, tourist cities are prone to traffic congestion, possibly due to the large amount of traffic during holidays (Gao, Cui, Xu, \& Bian, 2019). In addition, tourism traffic has the characteristic of being explosive, which brings great traffic pressure to cities. Exploring the behavior of tourists from big data contributes to the spatial research and policy implementation of land use and traffic interaction. Based on the OD density of TAZs, accommodation land use, shopping land use and restaurant land use, regression models of the relationship between tourism traffic and non-tourism traffic and tourism land use are established, and the impact of various tourism land uses on traffic is studied. The results show that the most important factor affecting non-tourism traffic and tourism traffic is accommodation land use, followed by shopping land use. In addition, as tourism land use increases, the generation and attraction of urban traffic also increase, which may form local agglomerations and lead to traffic congestion. This is consistent with previous literature studies showing that commercial land use will attract and generate more trips (Pulugurtha et al., 2013; Song, Zhao, Zhong, Nielsen, \& Prishchepov, 2019; Wang et al., 2019). However, during the tourism period, the impact of tourism land use on traffic is more significant and greater than that during the non-tourism period. Moreover, according to the travel links between the main travel nodes during the tourism period, traffic generation and attraction during the tourism period are very large and are mainly concentrated in the old town. During the tourism period, there was much more tourism traffic to and from major nodes than during the non-tourism period. That is, the connections between the Xiamen International Cruise Terminal, Xiamen Railway Station, Zhongshan Road and shopping plazas were particularly more significant during the tourism period than during the non-tourism period.

The analysis of urban tourism and traffic phenomena is conducive to the study of urban tourism. This research considered the impact of tourism land use on tourism traffic. Research in the past has focused more on the relationship between daily traffic and land use, ignoring the particularity of holidays and the impact of tourism land use on tourism traffic. In addition, during holidays, the morning peak hour occurs later than during the non-tourism period, but the evening peak hour occurs earlier than during the non-tourism period. Being positively correlated with tourism traffic, accommodation land use and shopping land use have great impacts on tourism traffic and will significantly increase the volume of tourism traffic. Therefore, during land use planning, attention should be given to the change in land use around scenic spots. In Xiamen, accommodation and restaurant are chiefly concentrated around the main attractions and transportation hubs, which are the main origins and destinations of tourists; therefore, these areas attract many tourists, and the demand for transportation is large. In addition, the main activity in the peak hour in the old town has brought tremendous pressure on urban traffic. Moreover, shopping plazas are also destinations of tourists in the evening peak hour. Therefore, while planning and performing the traffic management of tourist cities, the balance between accommodation land use, restaurant land use and shopping land use must be considered to alleviate the burden of urban traffic and other public services facilities during peak hours. Furthermore, the land use quotas of a tourism city should be allocated according to the scale of tourism development and tourism demand adjusted according to actual conditions rather than strictly controlled (Mao et al., 2014). For example, 
according to historical tourism accommodation demand data, the total number of tourism accommodations and beds in the core and potential tourism areas can be adjusted and controlled. As a result of a series of dynamic and complex land use patterns, more attention should be given to land use change by the tourist industry. Hence, in order to truly realize the sustainable development of tourism, tourism development planning should coordinate with land use planning and consider the relationship between tourism traffic and land use.

Finally, some limitations of this study should be mentioned. First, limited by the availability of the data, travel data other than FCD data and detailed land use data are unavailable. If these data are available, the results will be more convincing. Second, in most existing studies, land use is represented by the area of land use (Bordoloi, Mote, Sarkar, \& Mallikarjuna, 2013; Manaugh \& Kreider, 2013), and this paper uses the accommodation room density of TAZs, the proportion of shopping land use of TAZs and the restaurant POI density of TAZs instead of land use area or intensity. Future research work will be devoted to an in-depth study of the impact of tourism land use development intensity on tourism traffic. In addition, this paper only discusses the impact of tourism land use on tourism traffic. The follow-up study will focus on the impact of different levels of service facilities on traffic.

\section{Acknowledgements}

This research is supported by the National Natural Science Foundation of China (52078224 and 51608209) and the Promotion Program for Young and Middle-aged Teachers in Science and Technology Research of Huaqiao University (ZQN-PY512). 


\section{References}

Alaigba, D., Soumah, M., \& Banjo, M. (2017). Heterogeneity index for the assessment of relationship between land-use pattern and road traffic congestion in Apapa-Oworoshoki Express Way, Lagos Metropolis. ISPRS - International Archives of the Photogrammetry, Remote Sensing and Spatial Information Sciences, XLII-1/W1, 189-196. https://doi.10.5194/isprs-archives-XLII-1-W1-189-2017

Bi, L. (2015). Evaluation of ecological tourism land-use benefit based on the coupling relationship. Paper presented at the International Conference on Economics, Social Science, Arts, Education and Management Engineering, Xi'an, Shaanxi, China.

Boavida-Portugal, I., Rocha, J., \& Ferreira, C. C. (2016). Exploring the impacts of future tourism development on land use/cover changes. Applied Geography, 77, 82-91. https://doi.org/10.1016/j. apgeog.2016.10.009

Bordoloi, R., Mote, A., Sarkar, P. P., \& Mallikarjuna, C. (2013). Quantification of land-use diversity in the context of mixed land use. Procedia - Social and Behavioral Sciences, 104, 563-572. https://doi. org/10.1016/j.sbspro.2013.11.150

Gan, Z., Feng, T., Wu, Y., Yang, M., \& Timmermans, H. (2019). Station-based average travel distance and its relationship with urban form and land use: An analysis of smart card data in Nanjing City, China. Transport Policy, 79, 137-154. https://doi.org/10.1016/j.tranpol.2019.05.003

Gao, Y., Chen, S., Zheng, C., \& Bian, J. (2016). Road network capacity of tourist site’s periphery based on FCD: Taking Xiamen Island as an example. Progress in Geography, 35, 1529-1539. (Chinese).

Gao, Y., Cui, G., Xu, C., \& Bian, J. (2019). Road traffic status in the surrounding of urban tourist attractions based on FCD. Economic Geography, 39(3), 225-231. (Chinese).

Han, P. (2012). A study of roundabout traffic flow distribution based on the attraction of land use. Paper presented at the World Automation Congress (WAC), Puerto Vallarta, Mexico.

Kii, M., Moeckel, R., \& Thill, J.-C. (2019). Land use, transport, and environment interactions: WCTR 2016 contributions and future research directions. Computers, Environment and Urban Systems, 77, 101335. https://doi.org/10.1016/j.compenvurbsys.2019.04.002

Krause, C. M., \& Zhang, L. (2019). Short-term travel behavior prediction with GPS, land use, and point-of-interest data. Transportation Research Part B: Methodological, 123, 349-361. https://doi. org/10.1016/j.trb.2018.06.012

Łapko, A. (2014). Urban tourism in Szczecin and its impact on the functioning of the urban transport system. Procedia - Social and Behavioral Sciences, 151, 207-214. https://doi.org/10.1016/j.sbspro.2014.10.020

Liu, Y., Wang, F., Xiao, Y., \& Gao, S. (2012). Urban land uses and traffic 'source-sink areas': Evidence from GPS-enabled taxi data in Shanghai. Landscape and Urban Planning, 106(1), 73-87. https:// doi.org/10.1016/j.landurbplan.2012.02.012

Manaugh, K., \& Kreider, T. (2013). What is mixed use? Presenting an interaction method for measuring land use mix. Journal of Transport and Land Use, 6, 63-72. https://doi.10.5198/jtlu.v6i1.291

Mao, X., Meng, J., \& Wang, Q. (2014). Modeling the effects of tourism and land regulation on landuse change in tourist regions: A case study of the Lijiang River Basin in Guilin, China. Land Use Policy, 41, 368-377. https://doi.org/10.1016/j.landusepol.2014.06.018

Marzuki, A., Masron, T., \& Ismail, N. (2015). Land-use changes analysis for Pantai Chenang, Langkawi using spatial patch analysis technique in relation to coastal tourism. Tourism Planning \& Development, 13, 1-14. https://doi.10.1080/21568316.2015.1076507

Pulugurtha, S. S., Duddu, V. R., \& Kotagiri, Y. (2013). Traffic analysis zone level crash estimation models based on land-use characteristics. Accident Analysis \& Prevention, 50, 678-687. https://doi. 
org/10.1016/j.aap.2012.06.016

Song, J., Zhao, C., Zhong, S., Nielsen, T. A. S., \& Prishchepov, A. V. (2019). Mapping spatio-temporal patterns and detecting the factors of traffic congestion with multi-source data fusion and mining techniques. Computers, Environment and Urban Systems, 77, 101364. https://doi.org/10.1016/j. compenvurbsys.2019.101364

Spyratos, S., \& Stathakis, D. (2017). Evaluating the services and facilities of European cities using crowdsourced place data. Environment and Planning B: Urban Analytics and City Science, 45(4), 733-750. https://doi.10.1177/0265813516686070

Wang, X., Zhou, Q., Yang, J., You, S., Song, Y., \& Xue, M. (2019). Macro-level traffic safety analysis in Shanghai, China. Accident Analysis \& Prevention, 125, 249-256. https://doi.org/10.1016/j. aap.2019.02.014

Williams, A. M., \& Shaw, G. (2009). Future play: Tourism, recreation and land use. Land Use Policy, 26, S326-S335. https://doi.org/10.1016/j.landusepol.2009.10.003

Xi, J., Zhao, M., Ge, Q., \& Kong, Q. (2014). Changes in land use of a village driven by over 25 years of tourism: The case of Gougezhuang village, China. Land Use Policy, 40, 119-130. https:// doi:10.1016/j.landusepol.2013.11.014

Xiamen Municipal Bureau of Culture and Tourism. (2018). A survey of Spring Festival holiday tourism in Xiamen in 2018. http://wlj.xm.gov.cn/zwgk/tjxx/201907/t20190722_2318753.htm

Yu, C., \& He, Z.-C. (2017). Analyzing the spatial-temporal characteristics of bus travel demand using the heat map. Journal of Transport Geography, 58, 247-255. https://doi.org/10.1016/j.jtrangeo.2016.11.009

Yu, W., Ai, T., \& Shao, S. (2015). The analysis and delimitation of central business district using network kernel density estimation. Journal of Transport Geography, 45, 32-47. https://doi.org/10.1016/j. jtrangeo.2015.04.008

Zhang, T., Sun, L., Yao, L., \& Rong, J. (2017). Impact analysis of land use on traffic congestion using real-time traffic and POI. Journal of Advanced Transportation. https://doi.10.1155/2017/7164790

Zhu, Z., Xiong, C., Chen, X., He, X., \& Zhang, L. (2018). Integrating mesoscopic dynamic traffic assignment with agent-based travel behavior models for cumulative land development impact analysis. Transportation Research Part C: Emerging Technologies, 93, 446-462. https://doi.org/10.1016/j. trc.2018.06.011 